\title{
Investigate Polymer Flooding for Enhanced Oil Recovery in a Mature Oil Field
}

\author{
Hisham Khaled Ben Mahmud and Voon Yi Hung
}

Department of Petroleum Engineering, Curtin University Malaysia.

\begin{abstract}
Polymer flooding is the evolution of conventional water flooding technique. Instead of using just water to displace oil, polymer is used as an alternative to injection water. The polymer introduced to the injection water affects the viscosity of displaced fluid and hence decreases mobility ratio, improves stratification efficiencies and frontal saturations. The relative flow rates of water and oil are altered by the polymer solution, sweeping larger area of the reservoir and; therefore, more oil is in contact with the polymer solution and displaced to the production well. One of the principal purpose of this research is to examine the efficiency of polymer flooding in an oilfield by performing sensitivity analysis, which includes altering injection timing, polymer concentration, injection rate, injection layer, injection period and well configurations in a Western Australian oilfield. Also, water flooding is to be conducted as a base case to compare the efficiency of oil recovery for polymer flooding. A $7 x 7 \times 6$ box model was built and all the reservoir fluid data were analyzed using Computer Modeling Group (STARS). The results show that there is a slight increase in oil recovery (1.72\%) after polymer is injected. However, by changing the well configurations, a significant increment of $12.46 \%$ of oil recovery is observed.
\end{abstract}

Keyword: Enhanced oil recovery, modeling, oil recovery, CMG, polymer flooding.

\section{INTRODUCTION}

Generally, oil recovery options are divided into 3 main stages: primary, secondary and tertiary. Historically, the oil and gas industry describes these 3 stages of oil recovery in a chronological sequence. In the initial oil production stage, the primary oil recovery is resulted from displacement energy that occurs naturally in a reservoir. These natural driving mechanisms include depletion drive, gas cap drive, water drive and combination drive. After noticeable reduction in the initial oil production rate, secondary oil recovery takes place. The main purpose of secondary oil recovery is to control the pressure in the reservoir to maintain or increase the oil production rate by introducing external fluid to the reservoir. It is usually done with processes like water flooding or gas injection. Commonly, recovery factor from primary and secondary oil recovery is only around $20-40 \%$ and is affected by the reservoir rock properties, fluid properties as well as geological heterogeneities (Romero-Zerón, 2012). The third stage of the production, tertiary oil recovery, happens when the cost to production ratio of secondary oil recovery process is no longer economical. The ultimate intention for tertiary oil recovery is to improve the overall oil efficiency. In tertiary oil recovery, the recovery factor is about $30-60 \%$ (Sino Australia Oil and Gas Ltd, 2013). Also known as enhanced oil recovery, tertiary oil recovery increase hydrocarbon production by altering the formation properties for conducive extraction (Needham and Doe, 1987). The true meaning of enhanced oil recovery is the ultimate oil recovery that can be recovered from a reservoir in a cost-effective manner on top of the oil economically recovered from primary and secondary recovery oil processes. Over the years, research and pilot testing have been conducted to further develop different methods of enhanced oil recovery. These methods includethermal recovery and non-thermal methods, which consist of chemical flooding, miscible flooding, immiscible gas drives and microbial enhanced oil recovery.

Due to the reservoir oil phase-behavior properties, chemical processes often require the injection of chemical formulation in order to displace and mobilize oil effectively by decreasing the interfacial tension between oil and fluid. One of the most promising chemical processes is polymer flooding. Polymer flooding is the evolution of conventional water flooding technique. Instead of using just water to displace oil, polymer is used as an alternative to injection water. The polymer introduced to the injection water affects the viscosity of displaced fluid and hence decreases mobility ratio, 
improves stratification efficiencies and frontal saturations. The relative flow rates of water and oil are altered by the polymer solution, sweeping larger area of the reservoir and; therefore, more oil is in contact with the polymer solution and displaced to the production well. Implementing polymer flooding earlier at water breakthrough during water flood is more effective and efficient in recovering reservoir oil. Very often, polymers are used in addition to different enhance oil recovery processes. Polymer flooding provides the most efficient results when recovering moderately viscous oil in heterogeneous reservoir after water flood. Reservoirs that underwent water flooding with mobility ratio of less than one is more likely to have higher oil recovery due to better areal sweep efficiency. As vertical sweep efficiency improved, heterogeneous reservoir reacts positively to polymer flooding. Extended usage of polymer flooding can cause permanent damage to reservoir formation, causing a reduction in formation permeability (National Petroleum Council, 1984). Polymer solution is often injected first via the injection well to displaced the oil and followed by the drive water.

\subsection{Statement of Problem, Objectives and Limitations of Study}

One of the principal purpose of this research is to examine the efficiency of polymer flooding in an oilfield by performing sensitivity analysis, which includes altering injection timing, polymer concentration, injection rate, injection layer, injection period and well configurations. Also, water flooding is to be conducted as a base case to compare the efficiency of oil recovery for polymer flooding.

The main focus of this study is to examine the effect of polymer flooding in oil recovery. The effect of parameters such as polymer concentration, injection rate and injection time on oil recovery, configuration and location of wells are emphasized. Preliminary studies on economic aspect of polymer flooding is also performed. The limitation of the simulation is the large, active aquifer that sits under the oil reservoir which can results in the loss of polymer and can significantly increase the cost of polymer flooding.

\section{Methodology}

\subsection{Description of Reservoir Model}

The model is a 7x7x6 dimensions with an injection pattern of inverted five-spot (Figure 1), homogeneous reservoir with a large aquifer underlying the reservoir. The reservoir data can be found in Appendix A for reference purposes.

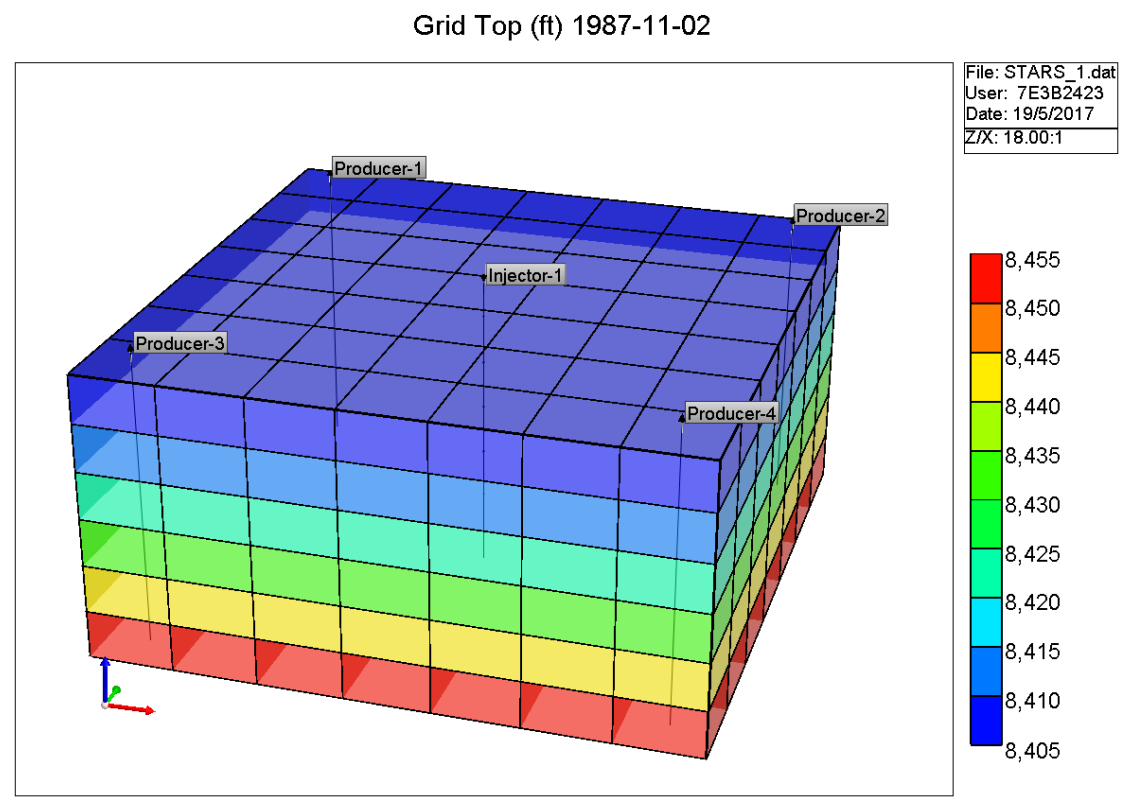

Figure1. Inverted 5-Spot Injection Pattern

The simulation was carried out in three stages. The first stage was to run the simulation from the initial until the end of production life without any secondary or tertiary oil recovery to monitor the recoverable oil. A few simulations were performed by closing perforation layer one by one from bottom to top of the reservoir to observe the reservoir water cut so that the timing for secondary and tertiary oil recovery method can be estimated. For the second stage, secondary oil recovery method 
(water flooding) was implemented. In order to determine the most optimum timing for secondary oil recovery, water flood was carried out at different years. A few injection rates were used in the simulation to study its effect on oil recovery. Polymer flooding (tertiary oil recovery) was performed in the third stage. With a reservoir temperature around $71.1^{\circ} \mathrm{C}$ and a high water salinity of 180000 ppm, the most suitable polymer identified to use for polymer flooding is Xanthan Gum. The best timing for polymer flooding was determined by running the simulation with different dates. Polymer concentration and polymer solution injection rate were varied in order to investigate its relationship with oil recovery. The optimization of well configurations and locations were conducted to check if an improved oil production was achieved. Lastly, the comparison of primary, secondary, tertiary oil recovery methods were grouped and compared to determine which method produces the highest oil recovery factor.

\section{RESUlTS \& DisCUSSION}

\subsection{Water Flooding}

A base case water flooding is carried out as a comparison to the polymer flooding scenarios. Two parameters were tested: Water flood timing and water flood injection rate. Based on the oil recovery factor for different water flood timing (Figure 2, Appendix B), it can be seen that the water flooding from November 1989 produces relatively more oil in the early stages. According to oil recovery factor for different water injection rate (Figure 3, Appendix B), it is observed that the injection rate of 2000 $\mathrm{bbl} / \mathrm{d}$ produces just slightly more water than the $1500 \mathrm{bbl} / \mathrm{d}$ injection rate. From both of the graphs, the best timing to do water injection is as earlier as possible (1989) and the best injection rate would be $1500 \mathrm{bbl} / \mathrm{d}$ as it uses less power from the pump to generate similar amount of oil.

\subsection{Polymer Flooding}

\subsubsection{Polymer Flood Timing}

A similar trend like the water flooding can be observed in the oil recovery factor graphs (Figure 4, Appendix B), when polymer flooding is performed from 1989, it produces relatively more oil than polymer flooding from 1992 and 1997. Hence, the earlier polymer flooding is done the higher the amount of oil is produced. The rationale behind this concept is the same as water flooding; the earlier polymer flooding is conducted, the more increase in sweep efficiency and ultimately improves oil recovery. Also note that at the point of injection for all three cases, the water cut (Figure 5, Appendix B) decreases slightly which cause oil production rate to increase marginally. This is because when polymer solution is injected more oil is produced instead of water. The best timing determined for polymer flooding starts from November 1989.

\subsubsection{Polymer Concentration}

Looking at Figure 6, Appendix B (oil recovery factor), it can be determined that polymer concentration of $5000 \mathrm{ppm}$ yields the most oil, whereas polymer concentration of $500 \mathrm{ppm}$ yields the least oil. This result is due to the fact that an increase in polymer concentration causes polymer solution viscosity to increase. The viscous polymer solution reduces mobility ratio and forms a pistonlike front that displaces the oil effectively and efficiently. Observing the cumulation and oil recovery graphs once more, the increment of oil recovery decreases as polymer concentration increases gradually. This conveys that there is a threshold limit of polymer concentration that can be obtained until it causes polymer solution to be too viscous to displace the oil effectively. The polymer concentration that can maximize oil recovery with the least cost was determined as $2000 \mathrm{ppm}$.

\subsubsection{Polymer Solution Injection Rate}

In line with the oil recovery factor (Figure 7, Appendix B), it can be seen that polymer solution injection rate has a positive effect on oil recovery. Polymer solution injection rate of $2000 \mathrm{bbl} / \mathrm{d}$ produces the highest volume of oil, coming in next is $1500 \mathrm{bbl} / \mathrm{d}$, then $1000 \mathrm{bbl} / \mathrm{d}$ and lastly $500 \mathrm{bbl} / \mathrm{d}$. High injection rate increases the volume of polymer solution pumped into the reservoir, hence more oil is displaced effectively. At the same time, as more volume of polymer solution is pumped into the reservoir it causes an increase in reservoir pressure which consequently produces extra oil, but the injection rate should not be too high that it causes reservoir pressure to exceed the initial reservoir pressure. The most cost-effective injection rate chosen for polymer flooding is $1000 \mathrm{bbl} / \mathrm{d}$ because a cheaper pump can be used to yield almost the same amount of oil as $1500 \mathrm{bbl} / \mathrm{d}$. 


\subsubsection{Polymer Flooding at Different Perforation Layer}

Initially polymer solution injection was carried out at one layer above oil-water contact with the rest of the perforation layers closed. Then the injection layer is moved a layer above, closing the rest. Conforming to Figure 8(Appendix B), the oil recovery factor, the differences between the results are minor. The justification of this sensitivity analysis is to reduce polymer loss to the strong aquifer by moving polymer solution injection further away from the aquifer (Brooks et al, 2010). However, the results show that even though polymer solution is moved further away from aquifer but it still produces oil less than polymer solution injection closest to aquifer. As suggested by the 3D result model for water saturation (Figure 9, Appendix B), within 5 years of production, it can be observed that layer 4, 5 and 6 has water saturation around 60 to $80 \%$. This means that the aquifer produces water that quickly floods the layers $(4,5,6)$, which causes inability to produce any significant result in oil recovery. This could be due to the sandstone formation which has high porosity and vertical permeability that encourages water to flood through. Thus, the best perforation layer to be injected with polymer solution is perforation layer 6 . The reason why injecting at perforation layer 6 is still able to produce marginally more oil than injecting at perforation layer 5 and layer 4 is because whether polymer solution is injected at layer 4 , layer 5 or layer 6 , most of the polymer solution is loss to aquifer water but because polymer solution is injected in layer 6 , in which the entire oil column is exposed to the polymer solution, it is able to displace more oil (from layer 1, 2, 3, 4, 5 and 6) compared to injecting at perforation layer 5 (from layer 1,2,3,4 and 5) and injecting at perforation layer 4 (from layer $1,2,3$ and 4).

\subsubsection{Polymer Solution Injection Period}

Based on the oil recovery factor (Figure 10, Appendix B) graph, it is illustrated that the injection of polymer solution for entire production life produces the highest amount of oil followed closely by injection of $1 \mathrm{PV}$ of polymer solution (5 years) then proceed with water flooding, injection of $0.5 \mathrm{PV}$ of polymer solution (3 years) then proceed with water flooding, injection of $1 \mathrm{PV}$ of polymer solution (5 years) with no water flooding and injection of $0.5 \mathrm{PV}$ of polymer solution (3 years) with no water flooding. The difference of oil recovery factor between the injection of polymer solution for entire production life and the other four cases are marginal. So, it can be safe to say that in this case, injection of $0.5 \mathrm{PV}$ of polymer solution (3 years) then proceed with water floodingis the best option since it produces oil close to the amount of that injection of polymer solution for entire production life (maximum amount of oil achievable by polymer flooding) but with a lot less polymer used, which can ultimately save cost.

\subsubsection{Well Configurations and Locations Optimization}

The 3D well configurations and locations of each cases are shown in Appendix C, Figure14 to Figure 19. Based on the Figure 11(Appendix B), it can be noticed that all cases with horizontal production well except for vertical production well produce similar result for both oil recovery factor (around $65 \%$ to 67\%). The rationalization of why horizontal production well works better than vertical production well is because of the water from the aquifer and the polymer solution tend to displace the oil to the top layer where the oil accumulates (Figure 12, Appendix B).

Another reason why horizontal well is more effective is because water-coning tends to occur in vertical production wells. Hatzignatiou and Mohamed (1994) states that water-coning often happen in a production well when water moves up towards the wellbore in the shape of a cone. The tendency of water coning occurring is proportional to the density difference between oil and the displaced fluid. Since polymer solution viscosity is higher than oil viscosity, water coning occurs. Also, it is because of the aspect ratio (Thomas et al, 2002). The reservoir has relatively thin thickness (60 ft) but a large radius and since a common boundary condition exist at the wellbore, the pressure gradient in radial direction will be smaller than the pressure gradient in axial direction. Hence, as aspect ratio decreases, the axial pressure gradient driving the water influx increases. There are several methods to reduce water coning (Jin, 2009):

(i) Improve the well productivity

(ii) Keep production rate below critical value (But often the critical oil production rate is too low to be economical for vertical well)

(iii) Using horizontal well 
(iv) Perforate the well above oil-water contact

(v) Inject polymer, resins or gel to create a permeability barrier between oil and water zones.

Due to less water coning, horizontal production wells positioned on the first layer of the reservoir are able to produce more oil compared to vertical production well. Although two horizontal production wells placed in between two horizontal injection wells yields the highest oil recovery factor but due to the complexity and high cost of horizontal injection and production wells, the logical option would be one vertical injection well with two horizontal production wells, where only one vertical injection well is used instead of two horizontal injection wells. Which is relatively simple and cheap but also producing roughly the same amount of oil.

\subsection{Comparison of Primary, Secondary and Tertiary Oil Recovery Results}

The best results for primary, secondary and tertiary oil recovery results are grouped and compared (Figure 13, Appendix B). It is observed the natural depletion with perforation layer 1, 2,3 open has the lowest oil recovery factor at $50.54 \%$. This oil recovery factor is considered high as most primary oil recovery method only managed to recover less than $30 \%$ of oil. The justification for this high oil recovery is due to the strong and active aquifer below the reservoir.

With the implementation of secondary oil recovery method (water flooding), the oil recovery factor was increased to 52.29\%. Singh and Kiel (1966) explained that under normal circumstances, unless reservoir size is huge or reservoir production rate is low, reservoir with strong natural water drive is not subjected to water flooding. This is because the reservoir has enough natural pressure to produce oil without any source of external energy. The best time to initiate a water flooding is when reservoir reaches bubble point pressure. At this specific pressure, the formation volume factor is at its highest point which can leave minimum stock tank barrels of oil trapped in reservoir. Also, the smallest value of oil viscosity can be achieved at bubble point pressure and thence reduces mobility ratio, enhance sweep efficiency and improves oil recovery. This statement can only be true when reservoir pressure is not allowed to go below bubble point pressure. However, for this particular reservoir the bubble point pressure is around $300 \mathrm{psi}$ to $500 \mathrm{psi}$, which is a huge difference from reservoir pressure even at the end of the production life of natural depletion (around $3700 \mathrm{psi}$ ). Based on the mobility ratio calculation, as shown in Table 5 (Appendix D), it can be noticed that when oil saturation in reservoir dropped to 0.7 (initial oil saturation is 0.8 ) in the reservoir, the mobility ratio exceeds one. This meant that mobility of injected water is higher than the mobility of oil. Viscous fingering had occurred in the reservoir in early stages of water flooding due to injection water bypassing the oil resulting in inefficient sweeping action. Thus, for this particular reservoir, water flood (secondary oil recovery method) is not an effective method to increase oil recovery.

A tertiary oil recovery (polymer flooding) was performed and the recovery factor of oil was improved slightly by $1.72 \%$ to $54.01 \%$ from water flooding and $3.47 \%$ from natural depletion. Based on the mobility ratio (Table 6, Appendix D) calculated the polymer solution viscosity obtained from a polymer concentration of $2000 \mathrm{ppm}$ is $25.85 \mathrm{cp}$, the mobility ratio exceeds 1 at 0.4 oil saturation. At the same oil saturation, the mobility ratio of polymer flooding is less than water flooding $(0.467<55.267)$. This is due to the fact that the viscosity of displaced fluid (polymer solution) has increased, which results in an increase volumetric sweep efficiency and ultimately more oil is recovered. Furthermore, the fractional water flow determined in both Table 5 and Table 6 also illustrates that at the same oil saturation, the fractional water flow for polymer flooding is lesser than the fractional water flow for water flooding. This mean that in polymer flooding more oil is being displaced effectively due to the piston-like flood front. Fluid diversion effect also plays a role in polymer flooding by building up resistance in the reservoir and cause the injected polymer solution to create another flow path to sweep the previously untouched zone in the reservoir.

However, the increased oil recovery factor from polymer flooding from water flooding is not significant. The reason behind this is due to water coning caused by the strong aquifer underlying the reservoir. Generally, horizontal wells are effective in naturally fractured formation and small thickness reservoirs with wide spacing (Leon-Ventura, Gonzalez and Leyva, 2000). According to Taber and Seright (1992) utilizing horizontal well is able to increase areal sweep efficiency by approximately $25 \%$ to $40 \%$. Therefore, by optimizing the well configuration from one vertical injection well with four vertical producer wells into one vertical injection well with two horizontal 
production wells, water coning can be prevented and more oil can be recovered. A massive $12.46 \%$ increment in result is displayed, which tops the oil recovery factor with $66.47 \%$ compare to all other methods.

\section{Conclusion}

In this study, the primary recovery of this reservoir is able to recover around $50.54 \%$ of oil, while performing secondary oil recovery (water flooding) is able recover $52.29 \%$, whereas tertiary oil recovery (polymer flooding) enables $54.01 \%$ of oil to be recovered. It was found that there is a strong and active aquifer underlying the reservoir, which results in early water breakthrough. Thus, polymer flooding is best carried out in the early stages of the reservoir production life to recover as much oil as possible before water cut gets too high. The most cost effective injection rate and polymer concentration determined is $1000 \mathrm{bbl} / \mathrm{d}$ and $2000 \mathrm{ppm}$ respectively. It was also found out that injecting $0.5 \mathrm{PV}$ of polymer solution followed by chase water produced similar result with injecting polymer solution for the whole production life with less cost. Due to the strong and active aquifer underlying the reservoir, water coning occurs and it was found out that vertical producers were not very effective. The high aspect ratio of the reservoir and water coning problem makes horizontal producer a logical solution to increase oil recovery factor. Ultimately, four vertical producers are replaced by two horizontal producers and the end result is $66.47 \%$ oil recovery factor, an astonishing $12.46 \%$ increment before optimizing well configuration

\section{Appendix A}

Table1. Reservoir Layers Data

\begin{tabular}{|c|c|c|c|c|}
\hline Layer & Permeability [mD] & Porosity (\%) & NTG & So \\
\hline Layer 5AA & 17 & $14 \%$ & 0.50 & $65 \%$ \\
\hline Layer 5AB & 68 & $19 \%$ & 0.32 & $69 \%$ \\
\hline Layer 5AC & 30 & $16 \%$ & 0.38 & $67 \%$ \\
\hline Layer 4 & 286 & $18 \%$ & 0.96 & $83 \%$ \\
\hline Layer 3A & 74 & $17 \%$ & 0.72 & $70 \%$ \\
\hline Layer 3B & 64 & $16 \%$ & 0.65 & $67 \%$ \\
\hline
\end{tabular}

Table2. Reservoir Layers Information

\begin{tabular}{|c|c|c|c|c|c|c|c|c|}
\hline & $\begin{array}{c}\text { Net } \\
\text { volume } \\
{\left[\mathbf{1 0}^{\mathbf{6}} \mathbf{~ m}^{\mathbf{3}}\right]}\end{array}$ & $\begin{array}{c}\text { Pore } \\
\text { volume } \\
{\left[\mathbf{1 0}^{\mathbf{6}} \mathbf{r m}^{\mathbf{3}}\right]}\end{array}$ & $\begin{array}{c}\text { HCPV } \\
\text { oil } \\
{\left[\mathbf{1 0}^{\mathbf{6}} \mathbf{r m}^{\mathbf{3}}\right]}\end{array}$ & $\begin{array}{c}\text { STOIIP } \\
{[\mathbf{M s t b}]}\end{array}$ & $\begin{array}{c}\text { Avg } \\
\text { NTG } \\
\text { Above } \\
\text { OWC }\end{array}$ & $\begin{array}{c}\text { Avg } \varphi \\
\text { Above } \\
\text { OWC }\end{array}$ & $\begin{array}{c}\text { Avg S } \\
\text { Above } \\
\text { OWC }\end{array}$ & $\begin{array}{c}\text { Avg } \\
\mathbf{S}_{\mathbf{w}} \\
\text { Above } \\
\text { OWC }\end{array}$ \\
\hline Layer 5AA & 50 & 7 & 3 & 13 & 0.28 & 0.14 & 0.43 & 0.57 \\
\hline Layer 5AB & 1,169 & 209 & 97 & 516 & 0.28 & 0.18 & 0.46 & 0.54 \\
\hline Layer 5AC & 2,502 & 445 & 187 & 994 & 0.47 & 0.18 & 0.42 & 0.58 \\
\hline Layer 4 & 3,800 & 692 & 433 & 2,308 & 0.95 & 0.18 & 0.63 & 0.37 \\
\hline Layer 3A & 5,232 & 822 & 407 & 2,170 & 0.80 & 0.16 & 0.50 & 0.50 \\
\hline Layer 3B & 1,462 & 251 & 68 & 359 & 0.90 & 0.17 & 0.27 & 0.73 \\
\hline Layer 2 & 11 & 1 & 0 & 0 & 0.34 & 0.09 & 0.00 & 1.00 \\
\hline Layer 1 & N/A & N/A & N/A & N/A & N/A & N/A & N/A & N/A \\
\hline
\end{tabular}

Table3. Relative Permeability and Capillary Pressure

\begin{tabular}{|c|c|c|c|}
\hline Sw & krw & kro & fw [krw/kro+krw] \\
\hline 0.001 & 0.000407 & 0.995707 & 0.000409 \\
\hline 0.01 & 0.005495 & 0.957704 & 0.005705 \\
\hline 0.1 & 0.074131 & 0.635686 & 0.104437 \\
\hline 0.2 & 0.162242 & 0.383078 & 0.297517 \\
\hline 0.3 & 0.256535 & 0.215735 & 0.543195 \\
\hline 0.4 & 0.355081 & 0.111186 & 0.76154 \\
\hline 0.5 & 0.456916 & 0.050766 & 0.900005 \\
\hline 0.6 & 0.56145 & 0.019447 & 0.966522 \\
\hline 0.7 & 0.668284 & 0.005644 & 0.991625 \\
\hline 0.8 & 0.777126 & 0.000987 & 0.998731 \\
\hline 0.9 & 0.887757 & $5.01 \mathrm{E}-05$ & 0.999944 \\
\hline 0.99 & 0.988707 & $2.51 \mathrm{E}-09$ & 1 \\
\hline
\end{tabular}


Investigate Polymer Flooding for Enhanced Oil Recovery in a Mature Oil Field

Table41. Reservoir Information

\begin{tabular}{|c|c|}
\hline Grid dimension & $7 \times 7 \times$ with 6 layers \\
\hline Water density & $62.4 \mathrm{Ib} / \mathrm{cuft}$ \\
\hline Oil density (stock tank) & $38.53 \mathrm{Ib} / \mathrm{cuft}$ \\
\hline Water compressibility & $3.3 \times 10^{-6} \mathrm{psi}^{-1}$ \\
\hline Rock compressibility & $5 \times 10^{-6} \mathrm{psi}^{-1}$ \\
\hline Water formation volume factor & $1 \mathrm{RB} / \mathrm{STB}$ \\
\hline Water viscosity & $0.7 \mathrm{cp}$ \\
\hline Oil viscosity & $1.34 \mathrm{cp}$ \\
\hline Reservoir temperature & $160^{\circ} \mathrm{F}$ \\
\hline Reservoir depth & $8150-8465 \mathrm{ft}$ \\
\hline Bubble point pressure & $300-500 \mathrm{psi}$ \\
\hline Reservoir pressure & $3915 \mathrm{psi}$ \\
\hline Oil formation volume factor & $1.18 \mathrm{Brb} / \mathrm{STB}$ \\
\hline Initial water saturation & 0.2 \\
\hline Initial oil saturation & 0.8 \\
\hline Wellbore radius & $0.375 \mathrm{ft}$ \\
\hline Effective drainage radius & $3000 \mathrm{ft}$ \\
\hline GOR & $60-205 \mathrm{scf} / \mathrm{bbl}$ \\
\hline WOC (water oil contact) & $8465 \mathrm{ft}$ \\
\hline API & $36.8-38 \mathrm{deg}$ \\
\hline Was content & $19 \%$ \\
\hline Pour point & $12-24^{\circ} \mathrm{C}$ \\
\hline Tar mat & $10-30 \mathrm{ft}$ \\
\hline Oil production & 1000 bopd \\
\hline Water cut & $50-81 \%$ \\
\hline Max oil column & $300 \mathrm{ft}$ \\
\hline Avg net pay & $60 \mathrm{ft}$ \\
\hline Water salinity & $180000 \mathrm{ppm}$ \\
\hline Average spacing & $2 \mathrm{~km}$ \\
\hline Average flowing WHP & $800 \mathrm{psi}$ \\
\hline
\end{tabular}

\section{Appendix B}
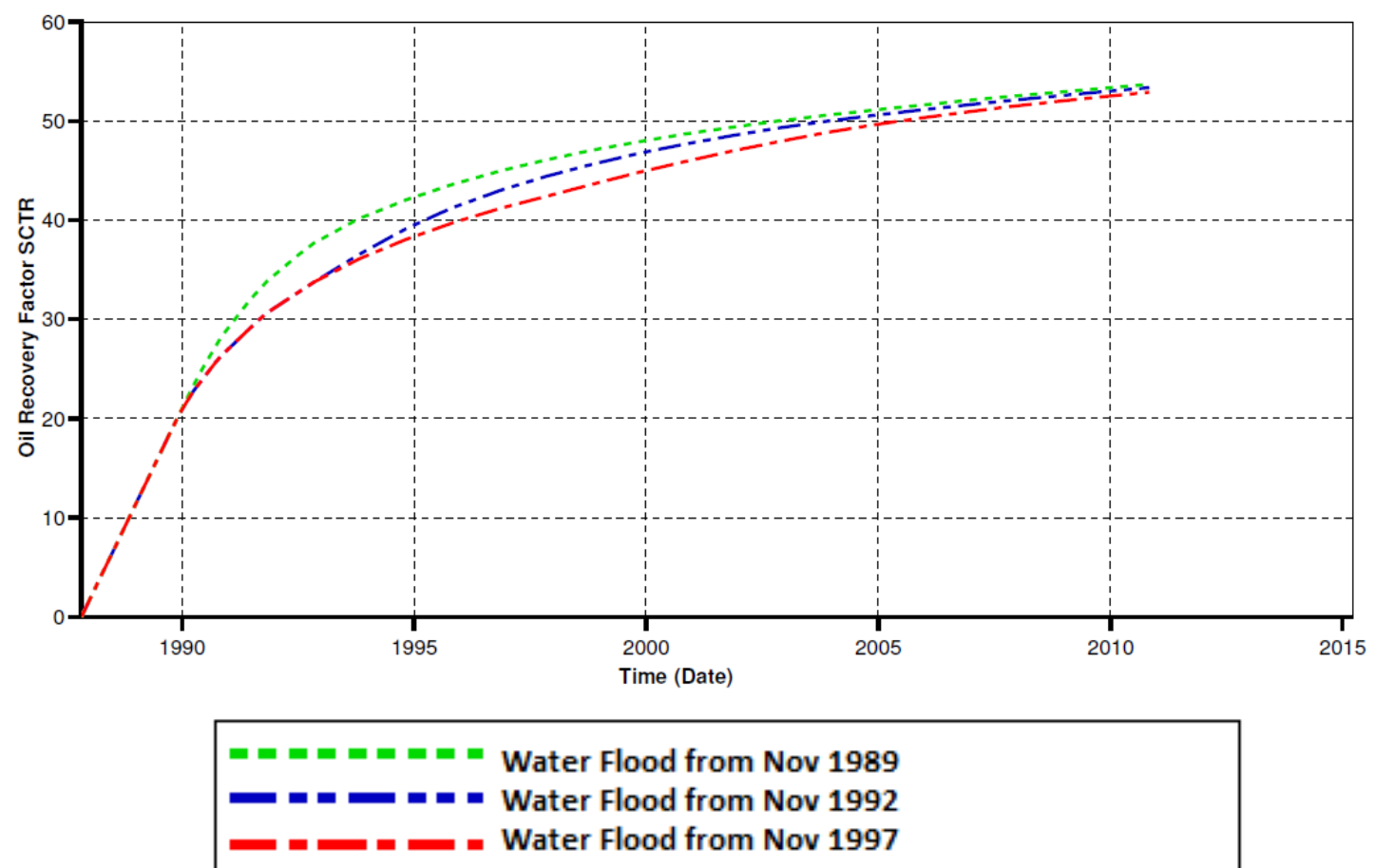

Figure2. Oil Recovery Factor for Different Water Flood Timing 


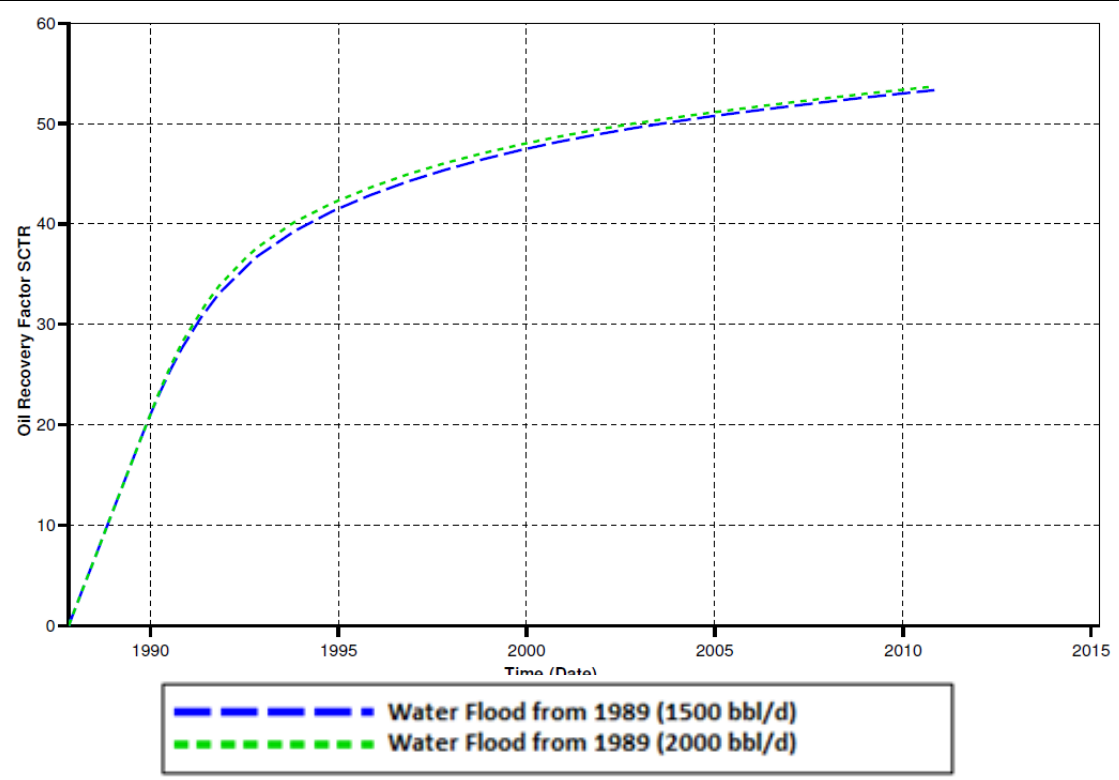

Figure3. Oil Recovery Factor for Different Water Injection Rate

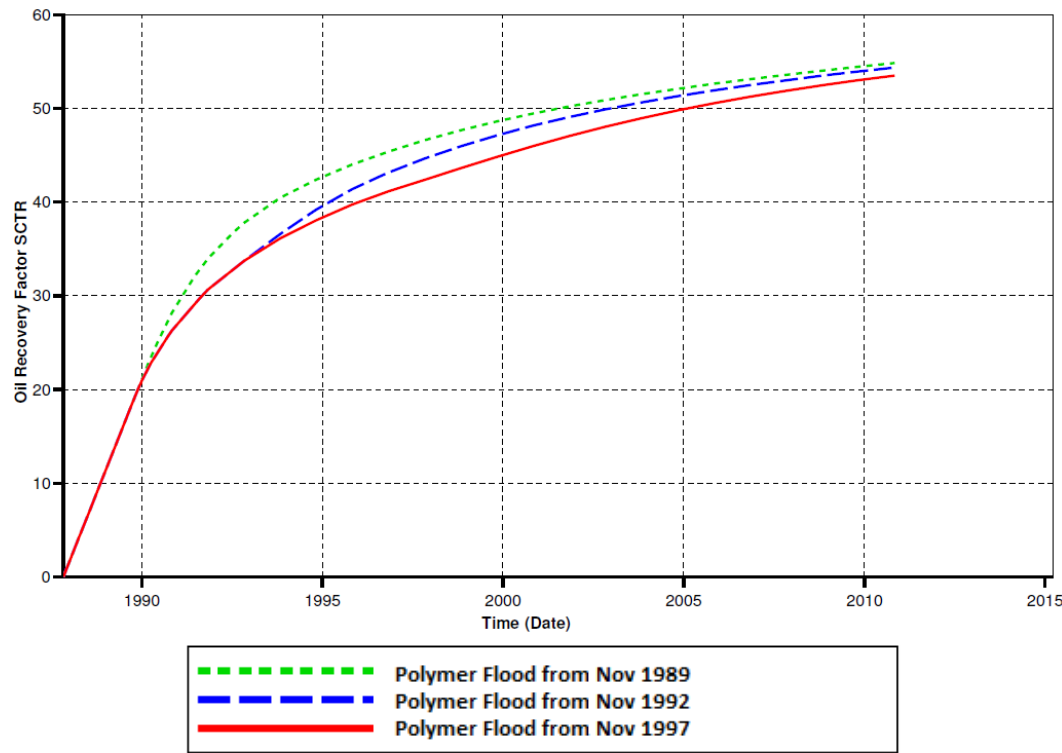

Figure4. Oil Recovery Factor for Different Polymer Flooding Timing

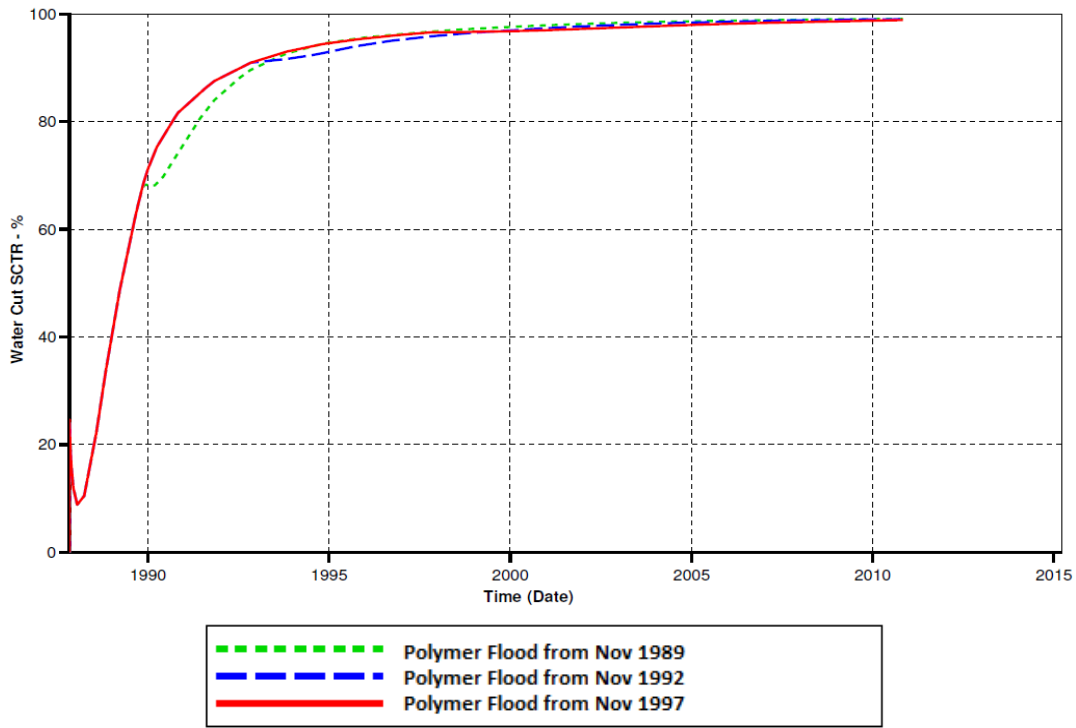

Figure5. Polymer Flooding Timing Water Cut 

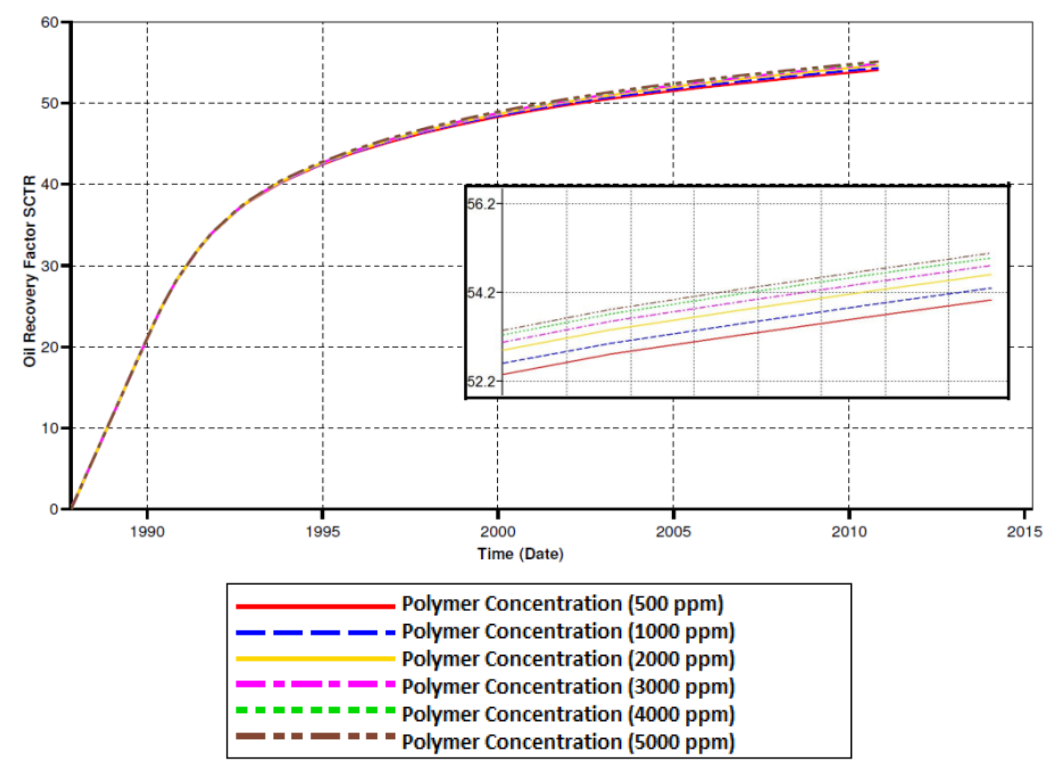

Figure6. Oil Recovery Factor for Different Polymer Concentration

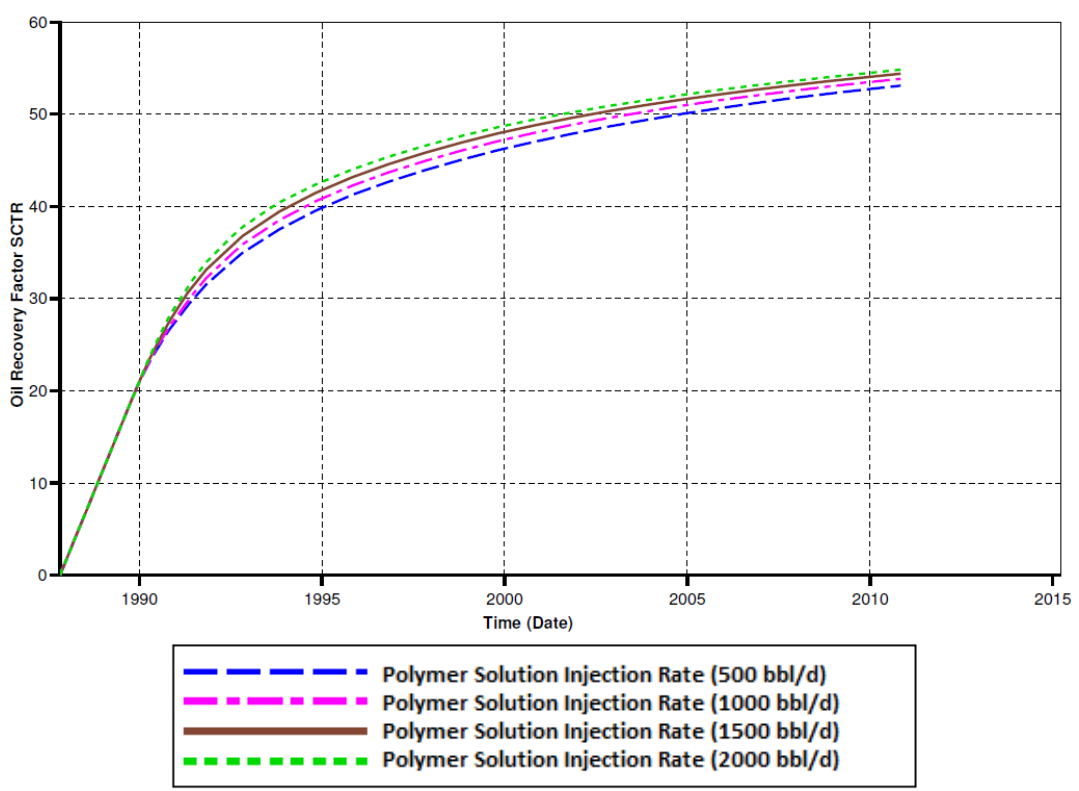

Figure7. Oil Recovery Factor for Different Polymer Solution Injection Rate

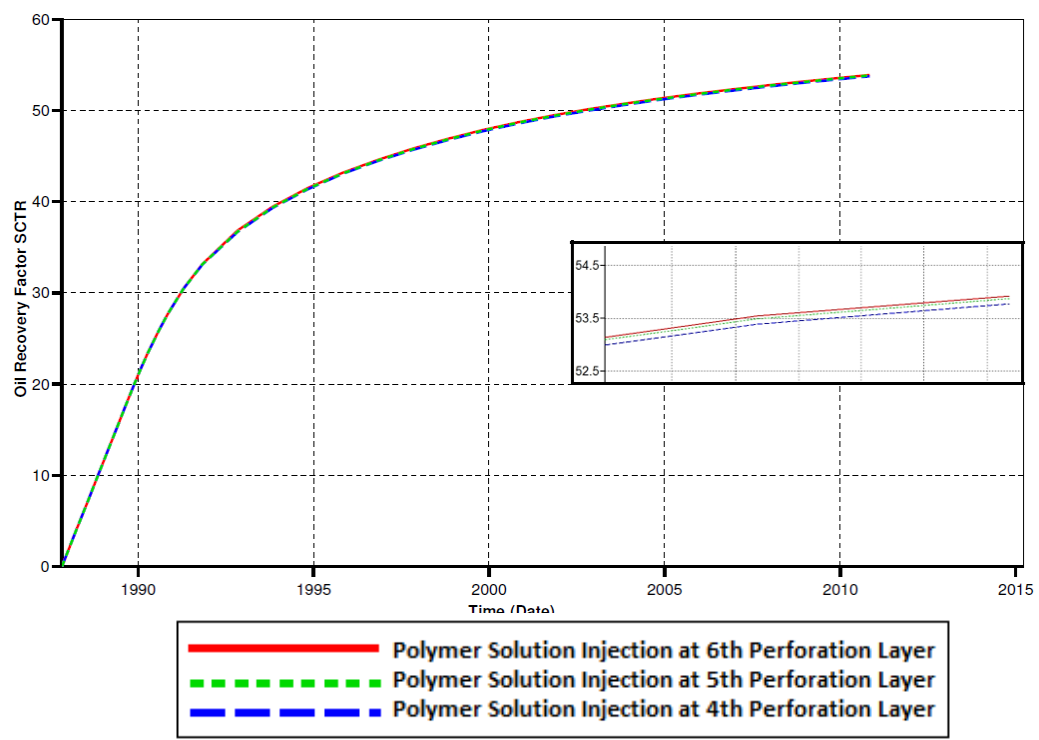

Figure8. Oil Recovery Factor for Polymer Flooding at Different Perforation Layer 
Water Saturation 1994-11-02

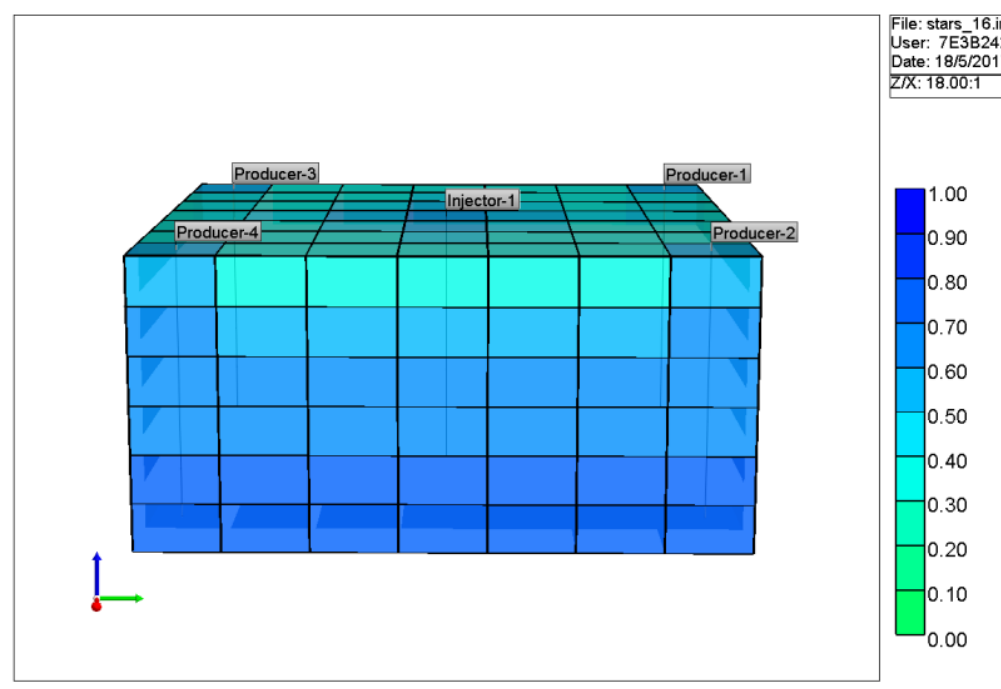

Figure9. 3D Illustration of Water Saturation after 5 Years

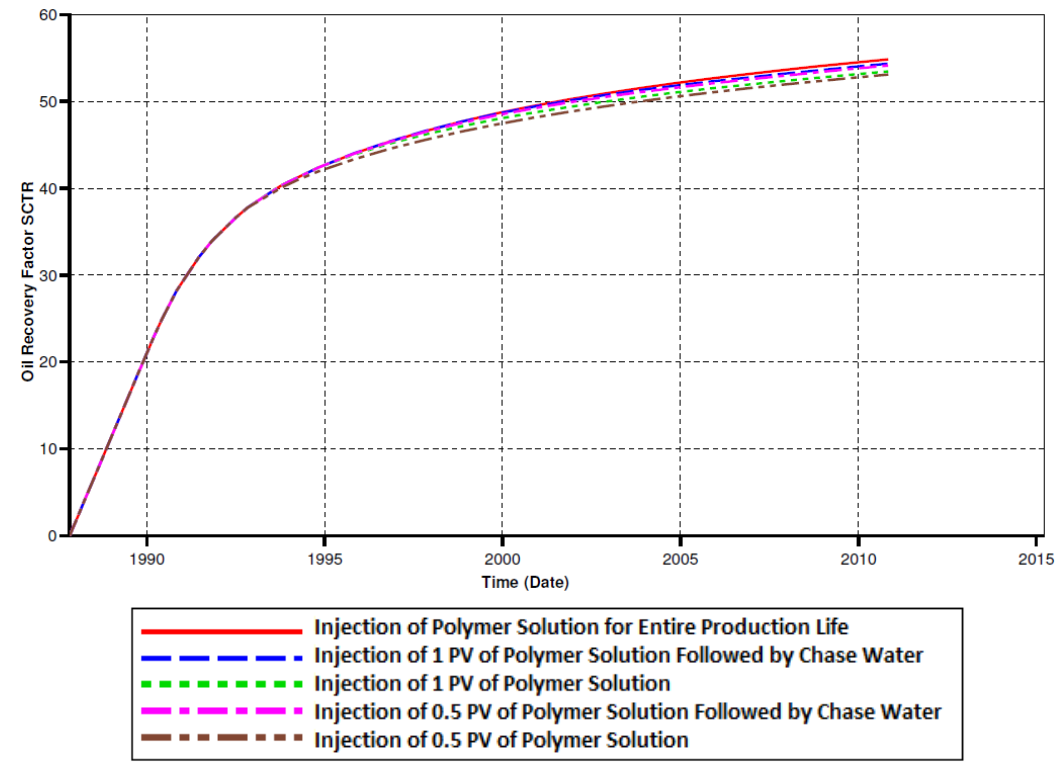

Figure10. Oil Recovery Factor for Different Polymer Flooding Method

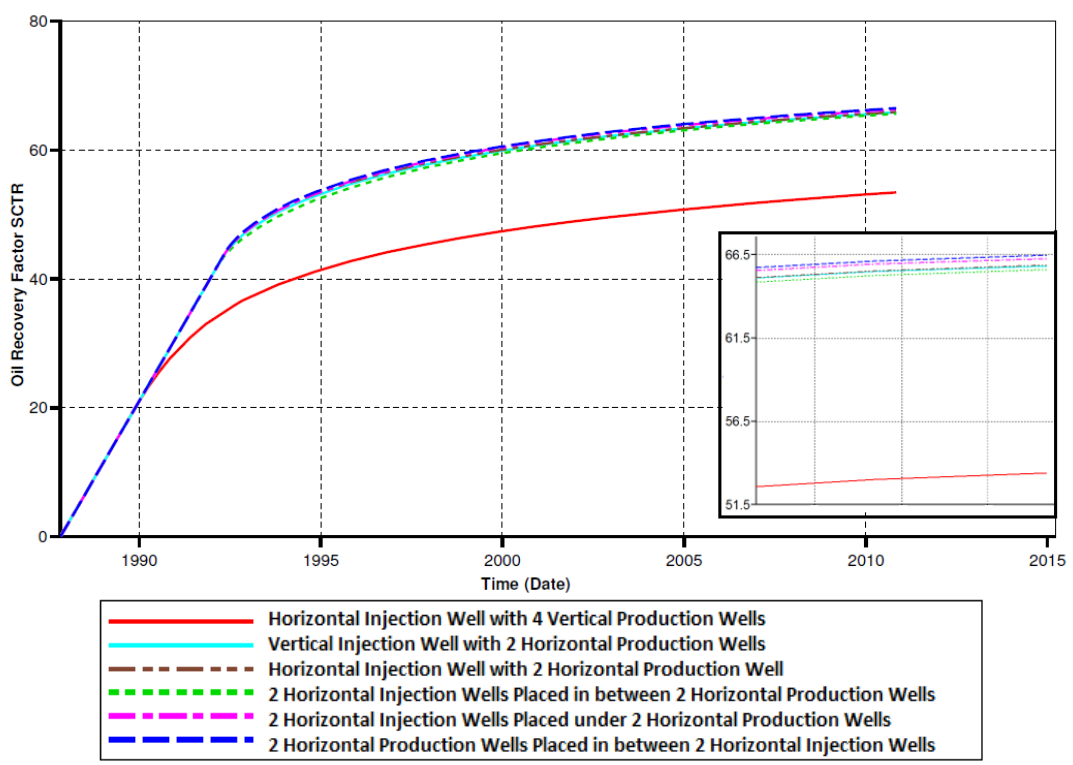

Figure11. Oil Recovery Factor for Different Well Configurations 


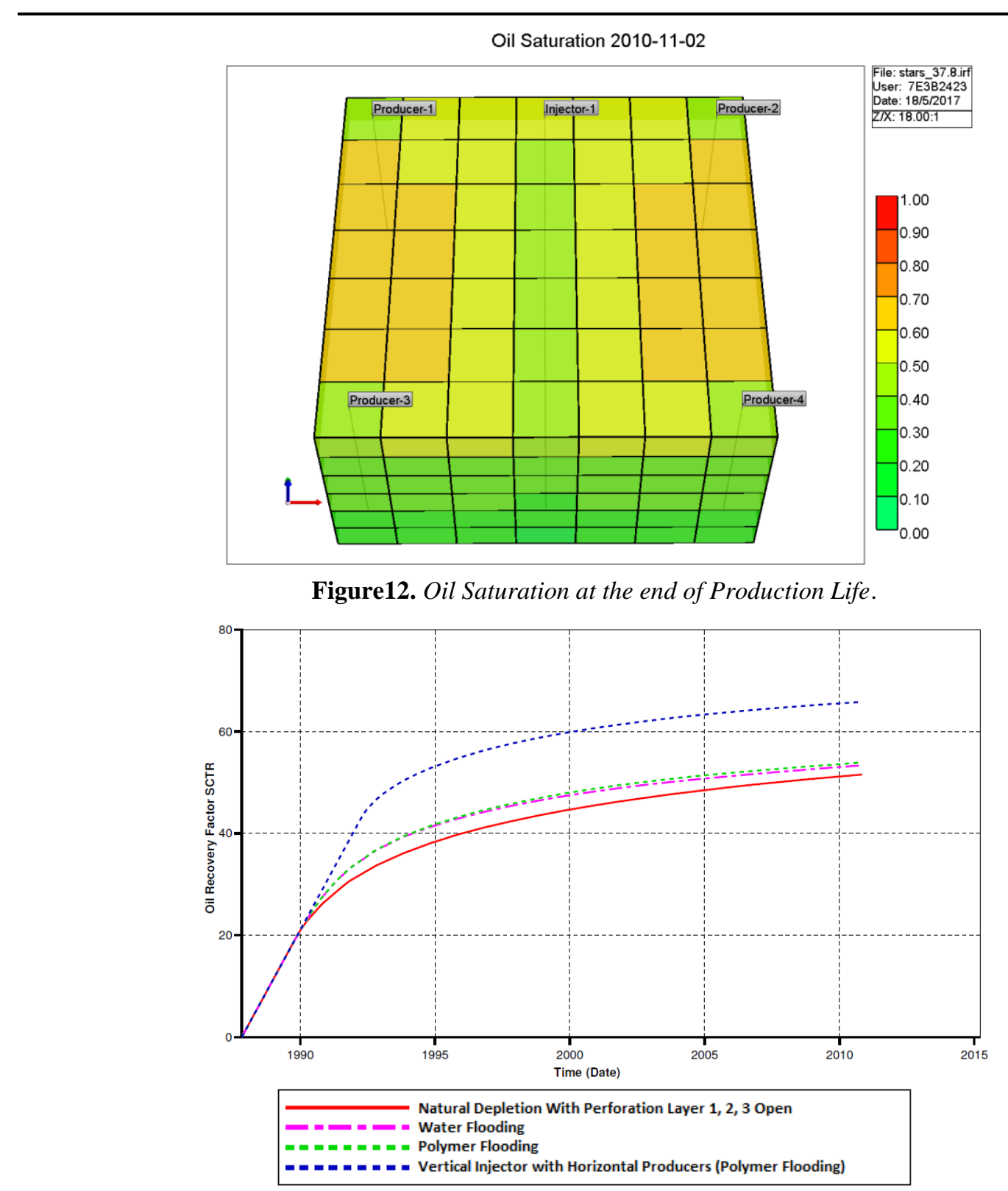

Figure13. Oil Recovery Factor for Primary, Secondary and Tertiary Oil Recovery

\section{Appendix C}

Grid Top (ft) 1987-11-02

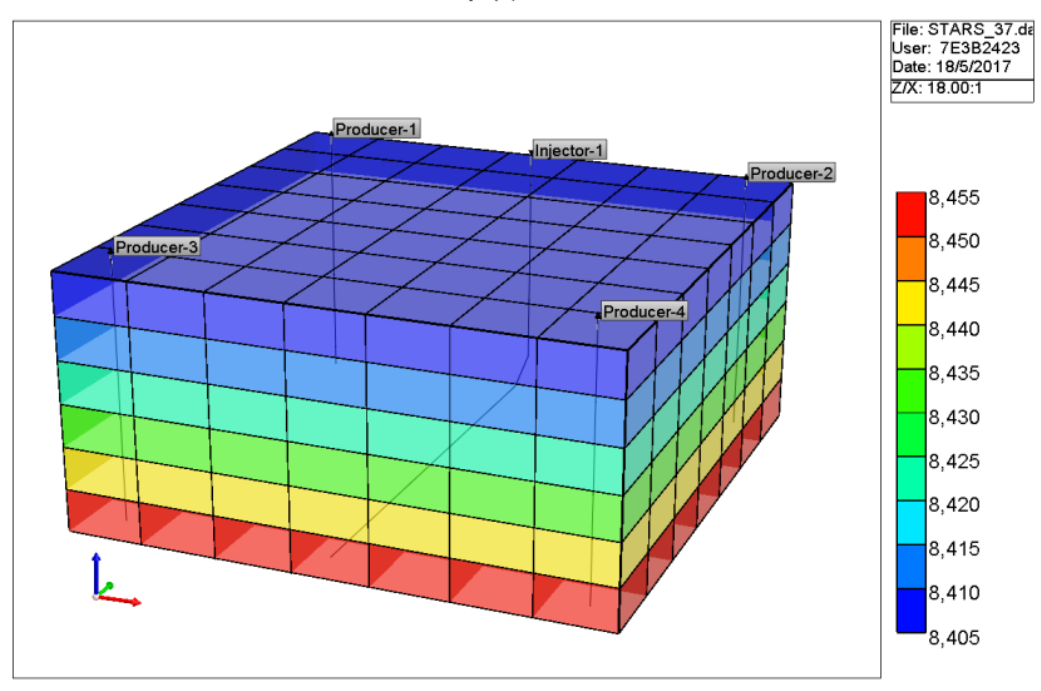

Figure14. 1 Horizontal Injector with 4 Vertical Producers. 


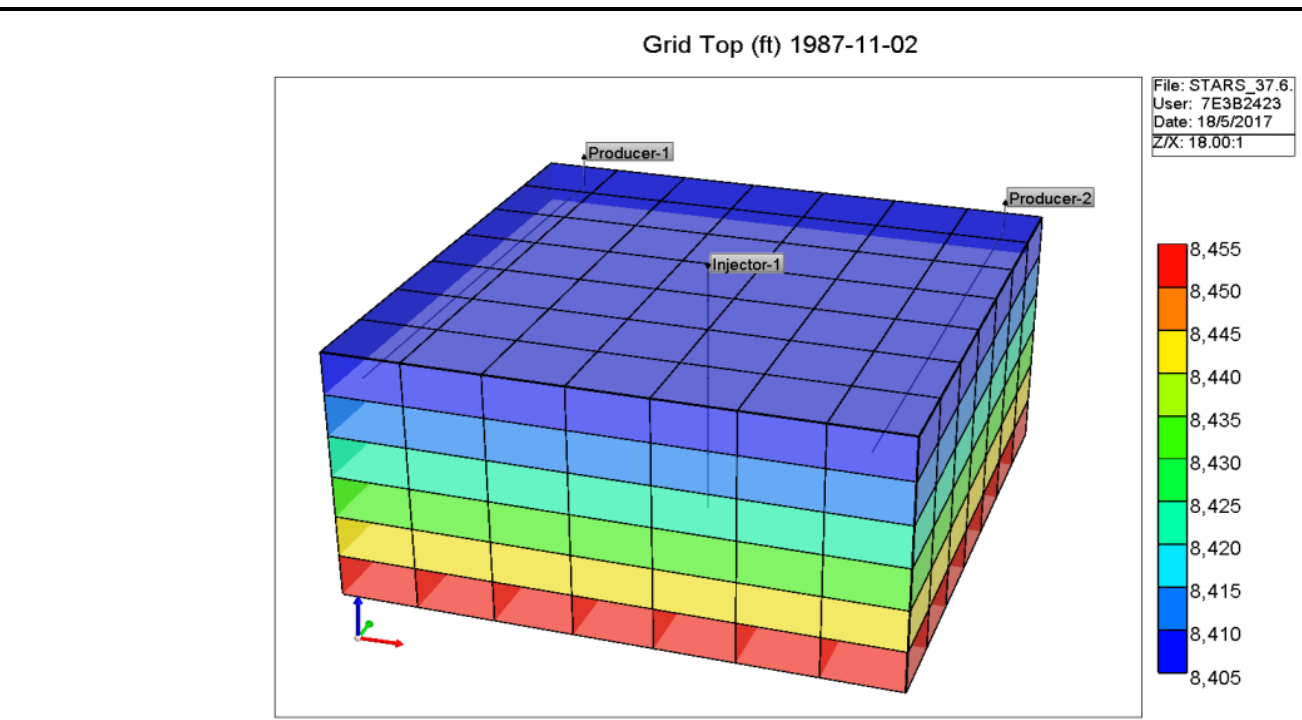

Figure15. 1 Vertical Injector with 2 Horizontal Producers.

Grid Top (ft) 1987-11-02

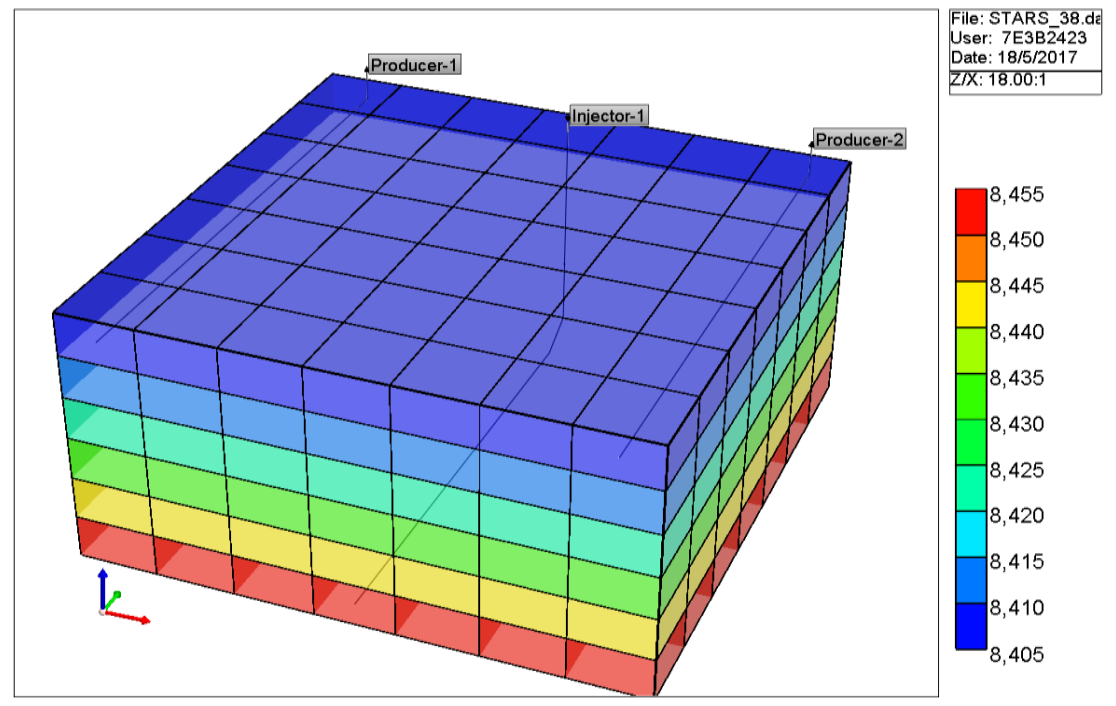

Figure16. 1 Horizontal Injectors with 2 Horizontal Producers.

Grid Top (ft) 1987-11-02

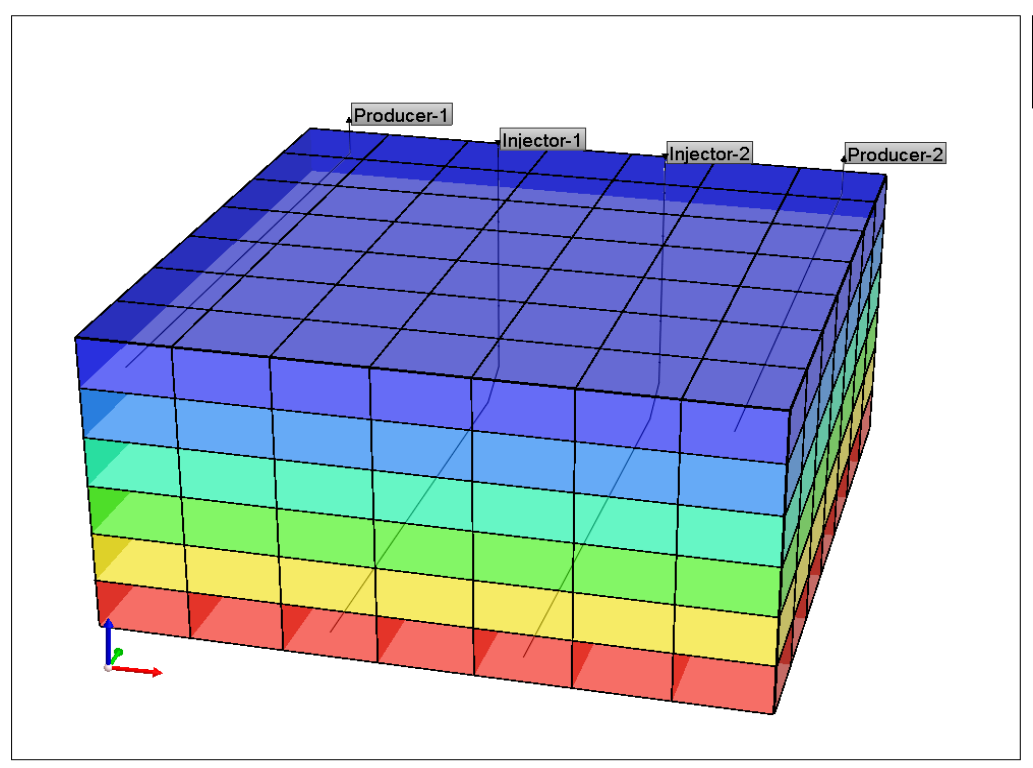

Figure17. 2 Horizontal Injector Placed in Between 2 Horizontal Producers. 
Grid Top (ft) 1987-11-02

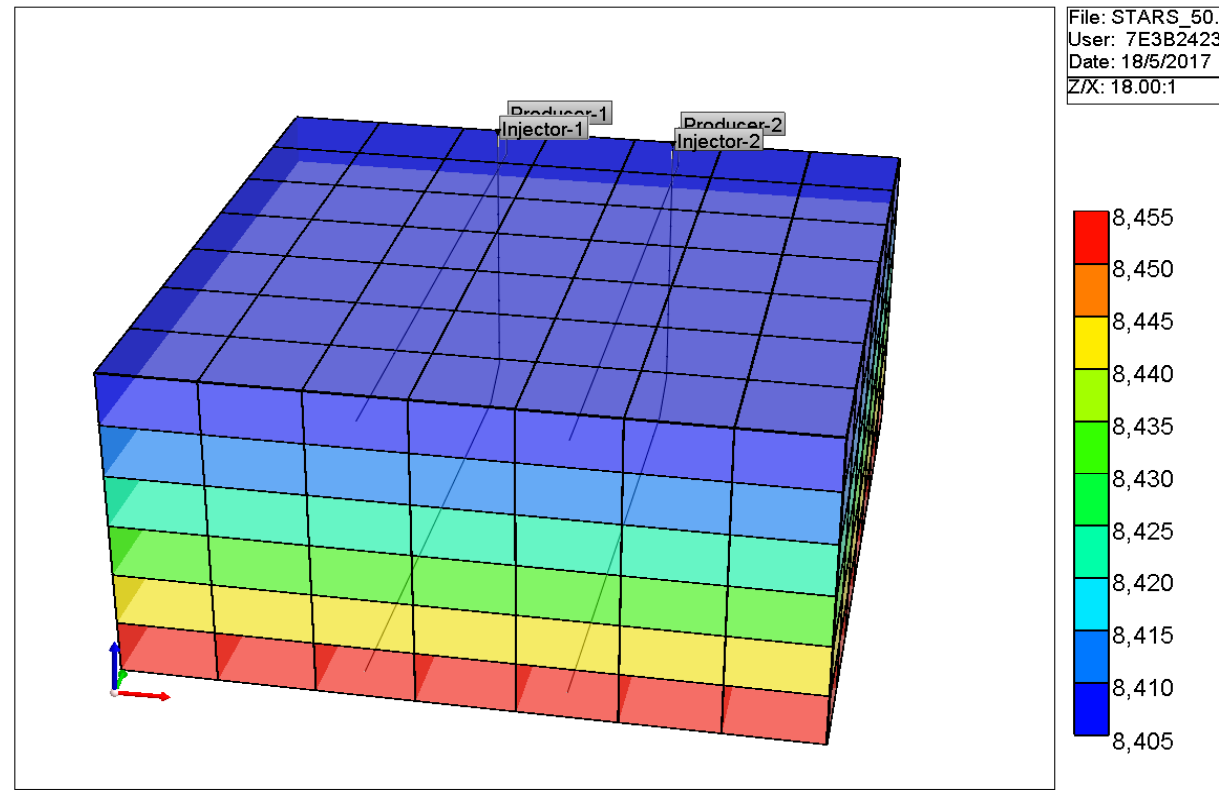

Figure18. 2 Horizontal Injectors Placed Under 2 Horizontal Producers.

Grid Top (ft) 1987-11-02

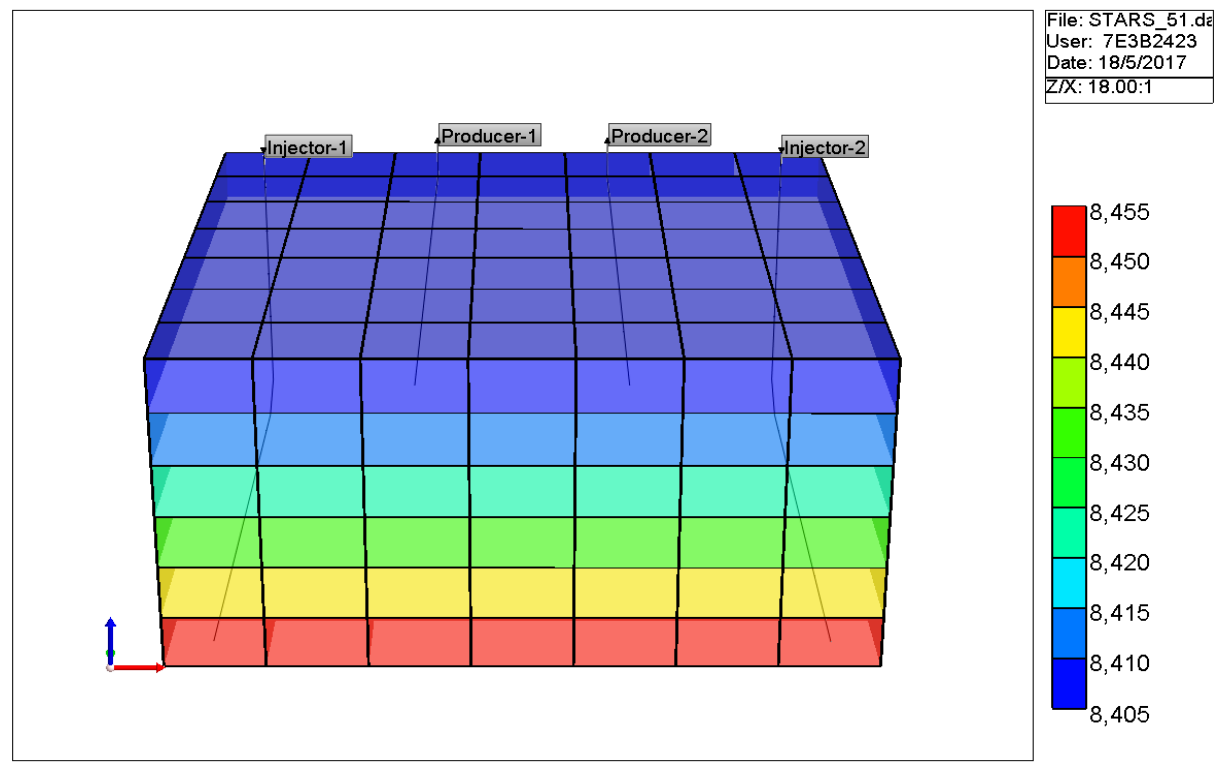

Figure19. 2 Horizontal Producers Placed in Between 2 Horizontal Injectors.

\section{Appendix D}

Table5. Mobility Ratio Calculation for Water Flooding

\begin{tabular}{|c|c|c|c|c|c|}
\hline $\mathbf{S}_{\mathbf{0}}$ & $\mathbf{S}_{\mathbf{w}}$ & $\mathbf{K}_{\mathbf{r w}}$ & $\mathbf{K}_{\mathbf{r o}}$ & $\mathbf{f}_{\mathbf{w}}$ & $\mathbf{M}$ \\
\hline 0.999 & 0.001 & 0.000407 & 0.995707 & 0.000781862 & 0.000782473 \\
\hline 0.99 & 0.01 & 0.005495 & 0.957704 & 0.010864233 & 0.010983561 \\
\hline 0.9 & 0.1 & 0.074131 & 0.635686 & 0.182496174 & 0.223235865 \\
\hline 0.8 & 0.2 & 0.162242 & 0.383078 & 0.447740303 & 0.810742311 \\
\hline 0.7 & 0.3 & 0.256535 & 0.215735 & 0.694779246 & 2.276317175 \\
\hline 0.6 & 0.4 & 0.355081 & 0.111186 & 0.859420603 & 6.113417928 \\
\hline 0.5 & 0.5 & 0.456916 & 0.050766 & 0.945143562 & 17.22940101 \\
\hline 0.4 & 0.6 & 0.56145 & 0.019447 & 0.982227567 & 55.26691594 \\
\hline 0.3 & 0.7 & 0.668284 & 0.005644 & 0.995607545 & 226.6630961 \\
\hline 0.2 & 0.8 & 0.777126 & 0.000987 & 0.999336973 & 1507.235258 \\
\hline 0.1 & 0.9 & 0.887757 & $5.01 \times 10^{-5}$ & 0.99997052 & 33920.56972 \\
\hline 0.01 & 0.99 & 0.988707 & $2.51 \times 10^{-9}$ & 0.999999999 & 754050870.8 \\
\hline
\end{tabular}


Hisham Khaled Ben Mahmud \& Voon Yi Hung

Table6. Mobility Ratio Calculation for Polymer Flooding

\begin{tabular}{|c|c|c|c|c|c|}
\hline $\mathbf{S}_{\mathbf{0}}$ & $\mathbf{S}_{\mathbf{w}}$ & $\mathbf{K}_{\mathbf{r w}}$ & $\mathbf{K}_{\mathbf{r}}$ & $\mathbf{f}_{\mathbf{w}}$ & $\mathbf{M}$ \\
\hline 0.999 & 0.001 & 0.000407 & 0.995707 & $2.11884 \times 10^{-5}$ & $2.11888 \times 10^{-5}$ \\
\hline 0.99 & 0.01 & 0.005495 & 0.957704 & 0.000297339 & 0.000297427 \\
\hline 0.9 & 0.1 & 0.074131 & 0.635686 & 0.006008748 & 0.006045072 \\
\hline 0.8 & 0.2 & 0.162242 & 0.383078 & 0.021482699 & 0.021954337 \\
\hline 0.7 & 0.3 & 0.256535 & 0.215735 & 0.058062075 & 0.061641084 \\
\hline 0.6 & 0.4 & 0.355081 & 0.111186 & 0.142033814 & 0.165547101 \\
\hline 0.5 & 0.5 & 0.456916 & 0.050766 & 0.318132312 & 0.466560182 \\
\hline 0.4 & 0.6 & 0.56145 & 0.019447 & 0.599453591 & 1.4965896 \\
\hline 0.3 & 0.7 & 0.668284 & 0.005644 & 0.859902357 & 6.137878811 \\
\hline 0.2 & 0.8 & 0.777126 & 0.000987 & 0.976085069 & 40.81488127 \\
\hline 0.1 & 0.9 & 0.887757 & $5.01 \times 10^{-5}$ & 0.998912506 & 918.5454082 \\
\hline 0.01 & 0.99 & 0.988707 & $2.51 \times 10^{-9}$ & 0.999999951 & 20419172.52 \\
\hline
\end{tabular}

\section{REFERENCES}

[1] Brooks, D., De Zwart, A. H., Bychkov, A., Azri, N., Hern, C., Al Ajmi, W., \& Mukmin, M. (2010, January 1). Evaluation Of EOR Techniques For Medium-Heavy Oil Reservoirs With a Strong Bottom Aquifer In The South Of Oman. Society of Petroleum Engineers. doi:10.2118/129149-MS

[2] Hatzignatiou, D. G., \& Mohamed, F. (1994, January 1). Water and Gas Coning in Horizontal and Vertical Wells. Petroleum Society of Canada. doi:10.2118/94-26

[3] Jin, L. (2009). Downhole Water Loop (DWL) Well Completion for Water Coning Control Theoretical Analysis. (Master's thesis, Louisiana State University and Agricultural and Mechanical College).

[4] Leon-Ventura, R., Gonzalez-G., G., \& Leyva-G., H. (2000, January 1). Evaluation of Horizontal Well Production. Society of Petroleum Engineers. doi:10.2118/59062-MS

[5] National Petroleum Council. (1984). Overview of Enhanced Oil Recovery Methods. Enhanced Oil Recovery. Washington, DC: National Petroleum Council

[6] Needham, R. B., and Doe, P. H. (1987). Polymer Flooding Review. Journal of Petroleum Technology, 39(12), 1503-1507. doi:10.2118/17140-PA

[7] Romero-Zerón, L. (2012). Advances in Enhanced Oil Recovery Processes. Introduction to Enhanced Oil Recovery (EOR) Introduction to Enhanced Oil Recovery (EOR) Processes and Bioremediation of Oil-Contaminated Sites (pp. 3-36). doi: 10.5772/45947

[8] Seright, R. S., Seheult, J. M., and Talashek, T. (2008). Injectivity Characteristics of EOR Polymers. Society of Petroleum Engineers. doi:10.2118/115142-MS

[9] Singh, S. P., \& Kiel, O. G. (1982, January 1). Water flood Design (Pattern, Rate, and Timing). Society of Petroleum Engineers. doi:10.2118/10024-MS

[10] Sino Australia Oil and Gas Ltd (2013). Enhanced Oil Recovery Technical Concepts. An Introduction to Enhanced Oil Recovery Techniques.

[11] Thomas, F. B., Shtepani, E., Marosi, G., \& Bennion, D. B. (2002, January 1). Production Well Water Coning-Is There Anything We Can Do? Petroleum Society of Canada. doi:10.2118/2002031 


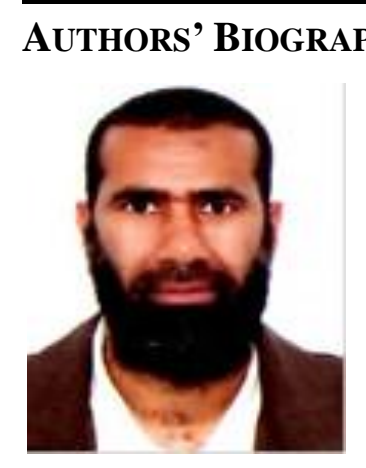

Hisham Khaled Ben Mahmud, has achieved Bachelor, Master and $\mathrm{PhD}$ degree in Chemical Engineering from Tripoli University, Sydney University and Curtin University, Australia, respectively. Also I have gained Graduate Diploma in oil and gas from University of Western Australia (UWA). I have expertise in modelling multiphase flow into subsea systems such as pipeline, jumper, riser evaluating pressure drop, and liquid holdup. Also optimize the risk of hydrate blockages into bend pipes. Recently I have involved into upstream research area including reservoir matrix acidizing, experimentally injecting a fluid (acid) into a core sample (sandstone or carbonate) to improve reservoir properties (porosity, permeability) observing wormhole and precipitation reaction. Another area I involve in is enhanced oil recovery (EOR) in brown oil field using different injecting fluids (CO2, water, polymer, surfactant) or modify production wells in order to improve hydrocarbon fluid recovery by minimizing oil wettability, surface tension and increase contact area.

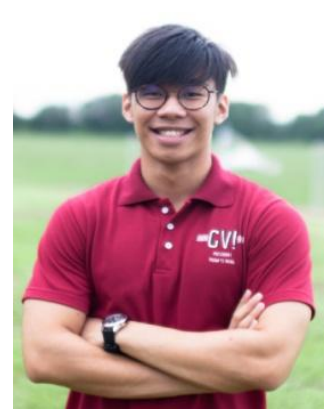

Voon Yi Hung, was born in Malaysia on October 18, 1994. He received the Bachelor of Engineering (Honors) in Petroleum Engineering from Curtin University, Malaysia. In 2015, he was awarded the Shell Scholarship by Shell. He was also part of the Committee of the Society of Petroleum Engineers Student Chapter Curtin University Malaysia for term 2015/2016 as he had organised a few site visits to Shell and Halliburton. He has emerged as a champion in the Enhanced Oil Recovery Simulation Competition held by University Technology Petronas in 2017. He pursued his internship in Petronas Carigali Sarawak Operations under the department of Well Intervention. Throughout his internship period he had contributed and involved in projects like Acid Stimulation, Gas Injection, Corrective and Preventive of Well Head Maintenance, Notice of Well Intervention Program and Specific Instructions for Special Operations, Daily updates of wireline activities. 